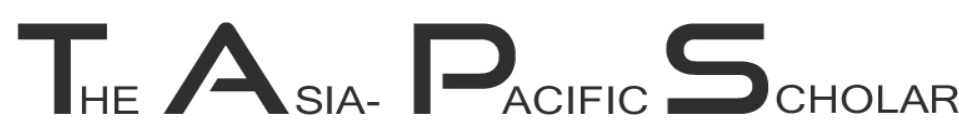 \\ MEDICAL AND HEALTH PROFESSIONS EDUCATION
}

\section{Depression and stressful life events among medical students during undergraduate career: Findings from a medical school in South Asia}

\author{
Dakshitha P. Wickramasinghe, Isuru S. Almeida \& Dharmabandhu N. \\ Samarasekera
}

Department of Surgery, Faculty of Medicine, University of Colombo

\begin{abstract}
Purpose: Medical students face significant psychological stress and adverse life events throughout their student career. The aim of this study was to assess the prevalence of depression among medical undergraduates in a medical faculty in Sri Lanka.

Methods: A cross-sectional study using a self-administrated, validated questionnaire was conducted among 300 undergraduate medical students of the University of Colombo, Sri Lanka. Prevalence of depression was assessed using Beck Depression Inventory (BDI). The data were analysed by the Mann-Witney U-test. P values less than 0.05 were considered statistically significant.

Results: Three hundred students participated in the study (male: female: 111: 189). Overall, 19\% (male: female: 25:32) of students were identified as depressed. Depression was most common among $1^{\text {st }}$ year $(25 \%)$ students followed by final year $(20 \%)$ and $3^{\text {rd }}$ year $(12 \%)$ students respectively. Depression was more common in students who were living in rented rooms compared to those residing in hostels and home $(22 \%, 19.1 \%$ and $13.3 \%$, respectively). Depression was less prevalent in students who participated in extracurricular activities than those who did not ( $11.9 \%$ vs $23.6 \%, P<0.05$, Mann-Whitney U-test). There were 2 students with extreme depression.

Multivariate analysis identified residency outside the city and adverse life events to be associated with a higher risk of depression and extracurricular activities to be associated with a lower risk.

Conclusions: $1^{\text {st }}$ year and female medical students had a higher prevalence of depression while those who participated in extracurricular activities had lower rates. A system should be established to identify students with depressive features early.
\end{abstract}

Keywords: $\quad$ Medical students, Depression, Stress, Sri Lanka

\section{Practice Highlights}

- Medical students have a higher prevalence of depression.

- Depression was seen less in students engaging in extracurricular activities.

\section{INTRODUCTION}

The increasing industrialisation in the $20^{\text {th }}$ century saw an increase in stress-related mental disorders (Rab, Mamdou, \& Nasir, 2008). By the year 2020, it is postulated that anxiety and depression will be only second to heart diseases in terms of disability worldwide (Lopez \& Murray, 1998). Medical students are confronted with stressful life events throughout their student career due to the quantum of material to be learnt and frequent academic evaluations (Mosley $\mathrm{Jr}$ et al., 1994). In addition, medical schools themselves are said to be stressful environments, which adversely affects students' academic performance and their physical and psychological wellbeing (Mosley Jr et al., 1994). 
Medical students have a higher rate of depression and stress than the general population (Rotenstein et al., 2016). Furthermore undergraduate medical students are the most distressed student group among all undergraduates (Rosenthal \& Okie, 2005; Sherina, Rampal, \& Kaneson, 2004). Two studies done in the USA using a questionnaire and cut-off values similar to the present study identified depression rates of $21.8 \%$ (Haglund et al., 2009) and 23.6\% (Ghodasara, Davidson, Reich, Savoie, \& Rodgers, 2011) among medical students.

Another study (Kulsoom \& Afsar, 2015) recognised that stress and depression were higher in medical students who are preparing for exams. There is evidence that depressive symptoms may worsen as they progress in their career (Newbury-Birch, Lowry, \& Kamali, 2002).

In addition, stress can adversely affect the academic performance (Melaku, Mossie, \& Negash, 2015; Sohail, 2013), lead to stress-induced disorders (Malathi \& Damodaran, 1999) and alcohol and substance abuse (Ball and Bax, 2002; Melaku et al., 2015). Therefore, students who are under extreme stress or depression need medical attention to prevent a cascade of troublesome consequences. Available evidence suggests that many of these psychological problems are under-diagnosed and under-treated, and may eventually lead to psychological morbidity (Tyssen, Vaglum, Grønvold, \& Ekeberg, 2001). Previous authors have also shown that mental health deteriorates after beginning medical school career and remains low throughout their training (Rosal et al., 1997), and may even continue later into the internship, postgraduate studies and later life (Ahmed, Banu, AlFageer, \& Al-Suwaidi, 2009).

The primary objective of this study was to determine the prevalence of depression and stressful life events among medical undergraduates. The secondary objective was to compare these findings with the first year, third year and final year medical students.

\section{METHODS}

\section{A. Subjects \& Setting}

A cross-sectional study was conducted at the Faculty of Medicine, University of Colombo, Sri Lanka, from June to August 2016. The undergraduate program spans over 5 years, with 3 academic terms every year. The students learn pre-clinical subjects in the first 3 terms. This is followed by a module based teaching in the $2^{\text {nd }}-4^{\text {th }}$ years (e.g. Cardio-vascular system, respiratory system) while simultaneously undergoing clinical training. The final year is almost entirely clinical training.
A self-administered questionnaire was distributed at a teaching activity where 100 students from the first, third and final year batches were present. These students represented the $1^{\text {st }}$ year, $3^{\text {rd }}$ year and final year who started their academic studies in 2015,2013 and 2011 respectively. All students returned completed questionnaires (100\% response rate) as it was distributed during a common teaching activity and the responses were collected at the end of the teaching session.

The objectives of the study were explained to the participants and returning a completed questionnaire was assumed to be implied consent. To ensure anonymity, the participants were instructed to refrain from including identifiers on the questionnaire.

Students with self-reported longstanding physical/ mental illnesses were excluded from the analysis.

\section{B. Instruments}

The self-administered questionnaire included demographic details, history of physical and mental illnesses before entering medical faculty and involvement in extracurricular activities. The students were also asked to complete the Beck Depression Inventory (BDI)(Beck, Steer, \& Brown, 1996).

The BDI is a 21-item self-report inventory. It can measure the severity of depression in adolescents and adults. The BDI was chosen to screen for depression in this study because of its well-established validity among medical undergraduates (Mancevska, Bozinovska, Tecce, Pluncevik-Gligoroska, \& Sivevska-Smilevska, 2007). Beck, Steer \& Carbin (1988) found a mean coefficient alpha of 0.86 and 0.81 for psychiatric and nonpsychiatric subjects, respectively.

The validated questionnaire consisted of 21 questions. The scale consists of items including depressive symptoms with intensities ranging from normal to extreme depression. We adopted the cut-off scores proposed by Mancevska et al. (2007). A cutoff point of 17 and above was used for detection of depression. BDI score of 31-40 was considered as severe depression and a score of above 40 was considered extreme depression.

A validated Sinhala version of the BDI is available (Rodrigo, Kuruppuarachchi, \& Pathmeswaran, 2015), but we decided to use the original English version because the undergraduate program is conducted in English. 


\section{Data analysis}

Statistical analysis was done using SPSS ${ }^{\circledR} \quad 21.0$ statistical software (SPSS Inc., USA) for Windows ${ }^{\circledR}$. Results of categorical variables were expressed as frequencies and proportions while continuous variables were expressed using means \pm standard deviations. Mann-Whitney U-test was used to compare data between groups. Logistic regression was used for multivariate analysis.

A P-value $<0.05$ was considered to be statistically significant.

\section{RESULTS}

\section{A. Demographic data}

All the students who were invited to participate returned a completed questionnaire (100\%). The sample consisted of 300 undergraduate students, including 111 (37\%) males and 189 (63\%) females from three batches. The mean age of the sample was $22.9(\mathrm{SD} \pm 1.89$, range 1728) years (Table 1).

\begin{tabular}{ccccc}
\hline \multirow{2}{*}{ Batch } & \multicolumn{2}{c}{$\begin{array}{c}\text { Number of } \\
\text { students }\end{array}$} & \multicolumn{2}{c}{ Mean age $( \pm$ SD years) } \\
& Male & Female & Male & Female \\
\hline \multirow{2}{*}{$1^{\text {st }}$ year } & \multirow{2}{*}{33} & 67 & $21(\mathrm{SD} \pm$ & $20.85(\mathrm{SD} \pm$ \\
& & & $0.68)$ & $1.1)$ \\
$3^{\text {rd }}$ year & 32 & 68 & $23(\mathrm{SD} \pm$ & $22.9(\mathrm{SD} \pm$ \\
& & & $1.14)$ & $1.19)$ \\
Final & \multirow{2}{*}{46} & \multirow{2}{*}{54} & $24.8(\mathrm{SD} \pm$ & $24.67(\mathrm{SD} \pm$ \\
year & & & $1.12)$ & $0.89)$ \\
\hline
\end{tabular}

Table 1. Gender and age distribution of the students of the three batches

Of the participants, $202(67.3 \%)$ were not residents of the city where the medical school is located, while 98 $(32.7 \%)$ were from the city and suburbs. One hundred and thirty-one $(43.7 \%)$ resided in the faculty hostels while $109(36.3 \%)$ and $60(20 \%)$ stayed in rented accommodation and in their own homes respectively (Table 2).

\begin{tabular}{ccccccc}
\hline \multirow{2}{*}{ Batch } & \multicolumn{2}{c}{ Home } & \multicolumn{2}{c}{ Residence } \\
& Male, $\mathbf{N}(\%)$ & Female, $\mathbf{N}(\%)$ & Male, N(\%) & Female, N(\%) & Male, N(\%) & Female, N(\%) \\
\hline $1^{\text {st }}$ year & $9(27.3 \%)$ & $15(22.4 \%)$ & $15(45.5 \%)$ & $46(68.7 \%)$ & $9(27.3 \%)$ & $6(9 \%)$ \\
$3^{\text {rd }}$ year & $2(6.3 \%)$ & $11(16.2 \%)$ & $9(28.1 \%)$ & $30(44.1 \%)$ & $21(65.6 \%)$ & $27(39.7 \%)$ \\
Final year & $9(19.6 \%)$ & $14(25.9 \%)$ & $8(17.4 \%)$ & $1(1.9 \%)$ & $29(63 \%)$ & $39(72.2 \%)$ \\
\hline
\end{tabular}

Table 2. Current residence of the students according to their gender

\section{B. Prevalence of medical student depression}

Overall, 57 (19\%) of students had a depression score more than 17 in the BDI. Of them, 25 (43.86\%) were male and 32 (56.14\%) were female. Depression was most prevalent among $1^{\text {st }}$-year students followed by the final year and $3^{\text {rd }}$-year students, respectively. However, the only statistically significant difference between these years was seen between the $1^{\text {st }}$ year and $3^{\text {rd }}$ year students (Chi-square test, $\mathrm{p}=0.028$ ) (Table 3 ).

\begin{tabular}{cccc}
\hline \multirow{2}{*}{ Batch } & \multicolumn{2}{c}{ Depression } & \\
& Male, & Female, & Total \\
& $\mathbf{N}(\%)$ & $\mathbf{N}(\%)$ & \\
\hline $1^{\text {st }}$ year & $10(30.3 \%)$ & $15(22.4 \%)$ & $25(25 \%)$ \\
$3^{\text {rd }}$ year & $6(18.8 \%)$ & $6(8.8 \%)$ & $12(12 \%)$ \\
Final year & $9(19.6 \%)$ & $11(20.4 \%)$ & $20(20 \%)$ \\
\hline
\end{tabular}

Table 3. Depression rates in three batches

Depression status was then categorized according to the BDI scale (Table 4). Of the 2 students who reported extreme depression, one was from the $1^{\text {st }}$ year and the other was from the final year.

\begin{tabular}{ccc}
\hline $\begin{array}{c}\text { Total } \\
\text { score }\end{array}$ & Levels of Depression & No of students \\
\hline $1-10$ & $\begin{array}{c}\text { These ups and downs are } \\
\text { considered normal }\end{array}$ & $181(60.31 \%)$ \\
$11-16$ & $\begin{array}{c}\text { Mild mood disturbance } \\
\text { Borderline clinical }\end{array}$ & $62(20.67 \%)$ \\
$17-20$ & depression & $20(6.67 \%)$ \\
$21-30$ & Moderate depression & $26(8.67 \%)$ \\
$31-40$ & Severe depression & $9(3 \%)$ \\
Over 40 & Extreme depression & $2(0.68 \%)$ \\
\hline Table 4. Level of depression according to BDI scale
\end{tabular}

There was a statistically significant difference in the BDI scores between the students who've had positive, negative and no major life events (Kruskal-Wallis test, $\mathrm{p}=0.001$ ). There was a statistically significant difference between the BDI scores between students with no major life events and negative life events (Mann-Whitney test, $\mathrm{U}=2561.5, \mathrm{p}<0.0001$ ) and between students who've had positive vs negative life events (Mann-Whitney test, $\mathrm{U}=444, \mathrm{p}=0.009$ ). There was no statistically significant difference between positive vs no major life events $(p=0.8)$. Students who did not engage in extracurricular activities had a higher likelihood of being depressed $(P<0.05)$. There was no statistically significant 
difference between residential status or a family history of mental illness with depression among students (Table 5).

\begin{tabular}{|c|c|c|c|}
\hline Variable & $\begin{array}{l}\text { Total No. of } \\
\text { respondents }\end{array}$ & $\begin{array}{c}\text { Depression } \\
\text { n (\%) }\end{array}$ & $P$ value \\
\hline \multicolumn{4}{|c|}{ Life events in last 6 months } \\
\hline - No & $226(75.4 \%)$ & $35(15.5 \%)$ & \multirow[t]{2}{*}{$P=0.08$} \\
\hline - Yes,Positive & $37(12.3 \%)$ & $7(18.9 \%)$ & \\
\hline - Yes,Negative & $37(12.3 \%)$ & $15(39.5 \%)$ & $P=0.09$ \\
\hline \multicolumn{4}{|l|}{ Residential status } \\
\hline • Home & $60(20 \%)$ & $8(13.3 \%)$ & \multirow[t]{2}{*}{$P=0.178$} \\
\hline - Rented rooms & $109(36.3 \%)$ & $24(22 \%)$ & \\
\hline - Hostel & $131(43.7 \%)$ & $25(19.1 \%)$ & $P=0.134$ \\
\hline \multicolumn{4}{|c|}{ Number of siblings } \\
\hline$\bullet 0$ & $29(9.7 \%)$ & $2(6.9 \%)$ & \\
\hline$\bullet 1-2$ & $217(72.4 \%)$ & $42(19.3 \%)$ & \\
\hline - 3-5 & $49(16.4 \%)$ & $12(24.5 \%)$ & \\
\hline$\bullet>5$ & $3(1 \%)$ & 0 & \\
\hline \multicolumn{4}{|c|}{ Family history of mental illness } \\
\hline - Yes & $12(4 \%)$ & $4(33.3 \%)$ & \multirow[t]{2}{*}{$P=0.958$} \\
\hline - No & $288(96 \%)$ & $53(18.4 \%)$ & \\
\hline \multicolumn{4}{|c|}{ Extracurricular activities } \\
\hline - Yes & $118(39.3 \%)$ & $14(11.9 \%)$ & \multirow{2}{*}{$P=0.000$} \\
\hline • No & $182(60.7 \%)$ & $43(23.6 \%)$ & \\
\hline
\end{tabular}

Table 5. Rate of self-reported depression among students and their social charasteristics

A logistic regression analysis was performed to identify independent risk and protective factors for depression. The logistic regression model was statistically significant $\left(\chi^{2}(3)=14.5, \mathrm{p}=0.002\right)$. However, the model only explained $10.9 \%$ (Nagelkerke $\mathrm{R}^{2}$ ) of the variance in the presence of depression and correctly classified $82.1 \%$ of cases. Students who were not originally from the city were 2.3 times more likely to have depression. Students who had an adverse life event also had a risk of depression twice that of other students who did not. Participation in extracurricular activities was associated with a $60 \%$ less chance of depression.

\section{DISCUSSION}

Medical students worldwide have a higher prevalence of depressive disorders compared to other undergraduates (Dyrbye, Thomas, \& Shanafelt, 2006). Medical training aims to prepare graduates for a personally rewarding career (Dyrbye et al., 2006). However, medical students also have high academic expectations and are expected to master an extensive range of knowledge and skills in a highly competitive environment. Therefore, it is understandable that medical students are the most distressed group of students among all undergraduates (Sherina et al., 2004).

The Asia Pacific Scholar, Vol. 4 No. 1 / January 2019 Copyright @ 2019 TAPS. All rights reserved.
Studies on medical students in other parts of the world have also identified a high frequency of depression (Moffat, McConnachie, Ross, \& Morrison, 2004; Rab et al., 2008). In a cross-sectional study done in Karachi, Pakistan, Inam, Saqib \& Alam (2003) identified that 60\% of students had anxiety and depression. Although there is a consensus that medical students have higher scores for depression, there is controversy about how these scores change over the undergraduate studentship. Several studies have shown that students may be the most depressed at the beginning of their course (Inam et al., 2003) - prevalence of depression higher among $1^{\text {st }}$ and $2^{\text {nd }}$ year students; depression highest among the $2^{\text {nd }}$ year students (Ahmed et al., 2009). However, in a recent meta-analysis Rotenstein (2016) failed to identify a difference between pre-clinical and clinical students.

Overall, $19 \%$ of the respondents in our sample were depressed by accepted BDI cutoffs. Compared to studies done in the region using BDI, this is similar to China (19\% depression) (Pan et al., 2016) while lower than the results of both Hong Kong (48\%)(Chan, 1991) and India (45\%) (Gupta \& Basak, 2013). However, both Chan (1991) and Gupta and Basak (2013) used a lower cut-off score to diagnose depression. We also observed that the rate of depression among our participants is higher than the $6.6 \%$ prevalence of depression in general population of Sri Lanka (Ball et al., 2010).

We found higher depression rates among female students than their male colleagues $(56.14 \%$ vs $43.86 \%, P>0.05)$. A similar pattern was seen in other many previous studies (Dyrbye et al., 2006; Tjia, Givens, \& Shea, 2005). However, a recent meta-analysis did not find the sex to significantly affect the depression scores (Rotenstein et al., 2016).

In addition, $1^{\text {st }}$-year students were more depressed than both final year and $3^{\text {rd }}$-year students. The same observation was met by other researchers as well (Tjia et al., 2005; Rab et al., 2008) and this may be due to the transition to the new environment (Inam et al., 2003; Rab et al., 2008), the new academic demands or getting mediocre results at exams (Rosenthal \& Okie, 2005). Rab et al. (2008) reported that depression was commoner in students with a history of negative life events in the recent past. In addition, those staying in university hostels were more depressed than those living in their own homes. These findings were comparable with our results as well. Multivariate analysis, however, did not find these factors to be independently associated with depression.

We found that students who did not engage in any extracurricular activities were significantly depressed 
than those who did. Even though the cross-sectional nature of our study prevents us from establishing a causality, participation of extra-curricular activities have been found to reduce school drop-out (Mahoney \& Cairns, 1997), lowering substance abuse and improving attitudes towards learning (Darling, 2005), improving school satisfaction (Gilman, 2001) and improve academic performance (Silliker \& Quirk, 1997). Therefore, we feel participation in extra-curricular activities should be promoted among university students.

The main limitation of our study was that we did not include other batches apart from $1^{\text {st }}, 3^{\text {rd }}$ and final year students due to the limited time factor. Also, the study was done in students from one medical school only. Furthermore, the study variables were measured by a self-reported questionnaire which does not allow diagnostic conclusions since some students will not reveal their psychiatric issues. Previous authors have consistently demonstrated a higher overall depression among the western population. However, the data is sparse for South Asia in this regard. Therefore, it was difficult to compare our findings with the data from the south Asian region. A longitudinal study would provide more robust data on how depression scores change as students advance in their training and we are designing such a study.

However, we feel that mechanisms should be established to identify vulnerable students early in their training period and to provide them support. This can be based on the risk factors identified in this study as well as others (Dwyer \& Cummings, 2001). In addition, carefully designed curricula aimed at reducing information overload might be helpful in preventing distress among undergraduates arising from the demands of tertiary education.

Simple interventions like physical exercise have been found to reduce depression (Lawlor \& Hopker, 2001) and can be easily implemented in Sri Lanka. Steinhardt and Dolbier (2008) reports of successful use of resilience intervention in decreasing symptoms of academic stress. A similar 4-week program could be incorporated into the introductory course all medical undergraduates follow prior to the commencement of the academic program.

\section{CONCLUSION}

Medical students had a higher prevalence of depression than the general population. Engaging in extracurricular activities was associated with a less chance of depression. To avoid the repercussions, teachers and administrators must explore the reasons, consequences and answers.

\section{Note on Contributors}

Dakshitha W., Isuru S. and Dharmabandhu N. S. designed the study. Dakshitha P. W. and Isuru S. A. collected the data. All authors were involved in data analysis, drafting the manuscript and approving the final manuscript.

\section{Ethical Approval}

Ethical approval for the study was obtained from the ethics review committee of the National Hospital of Sri Lanka.

\section{Funding}

There is no funding involved for this paper.

\section{Declaration of Interest}

None of the authors have any competing interests.

\section{References}

Ahmed, I., Banu, H., Al-Fageer, R., \& Al-Suwaidi, R. (2009). Cognitive emotions: Depression and anxiety in medical students and staff. Journal of Critical Care, 24(3), e1-e7. http://dx.doi.org/10.1016/j.jcrc.2009.06.003.

Ball, H. A., Siribaddana, S. H., Kovas, Y., Glozier, N., McGuffin, P., Sumathipala, A., \& Hotopf, M. (2010). Epidemiology and symptomatology of depression in Sri Lanka: A cross-sectional population-based survey in Colombo District. Journal of Affective Disorders, 123(1), 188-196.

http://dx.doi.org/10.1016/j.jad.2009.08.014.

Ball, S., \& Bax, A. (2002). Self-care in medical education: Effectiveness of health-habits interventions for first-year medical students. Academic Medicine, 77(9), 911-917.

Beck, A. T., Steer, R. A., \& Brown, G. K. (1996). Beck depression inventory-II (pp. 78204-72498). San Antonio, TX: Psychological Corporation.

Beck, A. T., Steer, R. A., \& Carbin, M. G. (1988). Psychometric properties of the Beck Depression Inventory: Twenty-five years of evaluation. Clinical Psychology Review, 8(1), 77-100. http://dx.doi.org/10.1016/0272-7358(88)90050-5.

Chan, D. W. (1991). Depressive symptoms and depressed mood among Chinese medical students in Hong Kong. Comprehensive Psychiatry, 32(2), 170-180.

Darling, N. (2005). Participation in extracurricular activities and adolescent adjustment: Cross-sectional and longitudinal findings. Journal of Youth and Adolescence, 34(5), 493-505. https://doi.org/10.1007/s10964-005-7266-8.

Dwyer, A. L., \& Cummings, A. L. (2001). Stress, self-efficacy, social support, and coping strategies in university students. Canadian Journal of Counselling, 25(3), 208-220.

Dyrbye, L. N., Thomas, M. R., \& Shanafelt, T. D. (2006). Systematic review of depression, anxiety, and other indicators of psychological distress among US and Canadian medical students. Academic Medicine, 81(4), 354-373. 
Ghodasara, S. L., Davidson, M. A., Reich, M. S., Savoie, C. V., \& Rodgers, S. M. (2011). Assessing student mental health at the Vanderbilt University School of Medicine. Academic Medicine, 86(1), 116-121. https://doi.org/10.1097/ACM.0b013e3181ffb056.

Gilman, R. (2001). The relationship between life satisfaction, social interest, and frequency of extracurricular activities among adolescent students. Journal of Youth and Adolescence, 30(6), 749767. https://doi.org/10.1023/a:1012285729701.

Gupta, S., \& Basak, P. (2013). Depression and type D personality among undergraduate medical students. Indian Journal of Psychiatry, 55(3), 287. https://doi.org/10.4103/0019-5545.117151.

Haglund, M. E., Aan Het Rot, M., Cooper, N. S., Nestadt, P. S., Muller, D., Southwick, S. M., \& Charney, D. S. (2009). Resilience in the third year of medical school: A prospective study of the associations between stressful events occurring during clinical rotations and student well-being. Academic Medicine, 84(2), 258268. https://doi.org/10.1097/ACM.0b013e31819381b1.

Inam, S., Saqib, A., \& Alam, E. (2003). Prevalence of anxiety and depression among medical students of private university. Journal of Pakistan Medical Association, 53(2), 44-46.

Kulsoom, B., \& Afsar, N. A. (2015). Stress, anxiety, and depression among medical students in a multiethnic setting. Neuropsychiatric Disease and Treatment, 11, 1713-1722. https://doi.org/doi/10.2147/NDT.S83577.

Lawlor, D. A., \& Hopker, S. W. (2001). The effectiveness of exercise as an intervention in the management of depression: Systematic review and meta-regression analysis of randomised controlled trials. The British Medical Journal, 322(7289), 763-770. https://doi.org/10.1136/bmj.322.7289.763.

Lopez, A. D., \& Murray, C. (1998). The global burden of disease. Nature Medicine, 4(11), 1241-1243. https://doi.org/10.1038/3218.

Mahoney, J. L., \& Cairns, R. B. (1997). Do extracurricular activities protect against early school dropout? Developmental Psychology, 33(2), 241-253.

Malathi, A., \& Damodaran, A. (1999). Stress due to exams in medical students-a role of Yoga. Indian Journal Of Physiology And Pharmacology, 43, 218-224.

Mancevska, S., Bozinovska, L., Tecce, J., Pluncevik-Gligoroska, J., \& Sivevska-Smilevska, E. (2007). Depression, anxiety and substance use in medical students in the Republic of Macedonia. Bratislavské Lekárske Listy, 109(12), 568-572.

Melaku, L., Mossie, A., \& Negash, A. (2015). Stress among medical students and its association with substance use and academic performance. Journal of Biomedical Education, 2015, 19. https://doi.org/10.1155/2015/149509.

Moffat, K. J., McConnachie, A., Ross, S., \& Morrison, J. M. (2004). First year medical student stress and coping in a problembased learning medical curriculum. Medical Education, 38(5), 482-491. https://doi.org/10.1046/j.1365-2929.2004.01814.x.

Mosley Jr., T. H., Perrin, S. G., Neral, S. M., Dubbert, P. M., Grothues, C. A., Pinto, B. M. (1994). Stress, coping, and wellbeing among third-year medical students. Academic Medicine, 69(9), 765-767.

Newbury-Birch, D., Lowry, R., \& Kamali, F. (2002). The changing patterns of drinking, illicit drug use, stress, anxiety and depression in dental students in a UK dental school: A longitudinal study. British Dental Journal, 192(11), 646-649.

Pan, X.-F., Wen, Y., Zhao, Y., Hu, J.-M., Li, S.-Q., Zhang, S.-K., ... Fu, C. (2016). Prevalence of depressive symptoms and its correlates among medical students in China: A national survey in 33 universities. Psychology, Health \& Medicine, 21(7), 882-889. https://doi.org/10.1080/13548506.2015.1127395.

Rab, F., Mamdou, R., \& Nasir, S. (2008). Rates of depression and anxiety among female medical students in Pakistan. Eastern Mediterranean Health Journal. 14(1), 126-33.

Rodrigo, A., Kuruppuarachchi, KALA, Pathmeswaran, A. (2015). Validation of the Beck Depression Inventory II among the Sinhalese speaking population in Sri Lanka. Sri Lanka Journal of Psychiatry, 6(2), 20-24.

Rosal, M. C., Ockene, I. S., Ockene, J. K., Barrett, S. V., Ma, Y., \& Hebert, J. R. (1997). A longitudinal study of students' depression at one medical school. Academic Medicine, 72(6), 542-546.

Rosenthal, J. M., \& Okie, S. (2005). White coat, mood indigo-depression in medical school. New England Journal of Medicine 353(11), 1085-1088. https://doi.org/10.1056/NEJMp058183.

Rotenstein L.S., Ramos M.A., Torre M., Segal J.B., Peluso M.J., Guille C., ..., Mata, D. A. (2016). Prevalence of depression, depressive symptoms, and suicidal ideation among medical students: A systematic review and meta-analysis. The Journal of American Medical Association, 316(21), 2214-2236. https://doi.org/10.1001/jama.2016.17324.

Sherina, M., Rampal, L., \& Kaneson, N. (2004). Psychological stress among undergraduate medical students. Medical Journal of Malaysia, 59(2), 207-211.

Silliker, S. A., \& Quirk, J. T. (1997). The effect of extracurricular activity participation on the academic performance of male and female high school students. The School Counselor, 44(4), 288293.

Sohail, N. (2013). Stress and academic performance among medical students. Journal of College of Physicians and Surgeons of Pakistan, 23(1), 67-71.

Steinhardt, M., \& Dolbier, C. (2008). Evaluation of a resilience intervention to enhance coping strategies and protective factors and decrease symptomatology. Journal of American College Health, $56(4), 445-453$.

Tjia, J., Givens, J. L., \& Shea, J. A. (2005). Factors associated with undertreatment of medical student depression. Journal of American College Health, 53(5), 219-224.

Tyssen, R., Vaglum, P., Grønvold, N. T., \& Ekeberg, Ø. (2001). Suicidal ideation among medical students and young physicians: A nationwide and prospective study of prevalence and predictors. Journal of Affective Disorders, 64(1), 69-79.

*Dharmabandhu N Samarasekera

Professor of Surgery and Senior Professor,

Faculty of Medicine, University of Colombo

Address of institution: Department of Surgery,

Faculty of Medicine, P.O. Box 271,

Kynsey Road, Colombo 8, Sri Lanka

Tel: $94-112671846$

Fax: $94-112671846$

Email: samarasekera58@yahoo.co.uk 